\title{
Migración y remesas familiares; nueva dependencia de la
} \section{economía.}

Por: Juan Carlos Grande y Jorge Barraza Ibarra

$\mathrm{L}$ as remesas familiares en El Salvador son un fenómeno reciente cuya importancia ha venido aumentando en los últimos años. Aproximadamente hace diez años, en forma coincidente con el momento en que se derrumban los precios internacionales de nues. tro principal producto de exportación: el café. Son resultado del peculiar proceso migratorio que acompaña la evolución de la economía en las últimas dos décadas. Se considera además que este fenómeno migratorio hacia el extranjero, especialmente a los Estados Unidos, aunque forma parte de un vasto movimiento de latinoamericanos hacia el pais de las esperanzas, en nuestro caso especial es motivado por dos causas fundamentales: la falta de oportunidades de empleo y el enorme diferencial de salarios entre El Salvador y el principal pais de destino, aunado a los diez años de guerra civil que afectó a muchas poblaciones de las zonas rurales, así como, a las zonas marginales de los centros urbanos.

Se estima que las remesas familiares producen ingresos de más de mil 800 millones de dólares anuales, ingresos que han permitido equilibrar el saldo desfavorable de la Balanza Comercial del pais y mostrar resultados aceptables en la cuenta corriente, evitando así, una permanente amenaza de devaluación del tipo de cambio, por la constante acumulación de reservas internacionales netas, cuyos resultados representan seis meses de importación.

Dichas remesas familiares han adquirido prof undas implicaciones en la vida nacional: el fenómeno no es exclusivamente económico, sino que tiene dimensiones sociales, familiares, politicas e institucionales. El ámbito de influencia, a nivel microeconómico, se refleja en muchas acrividades del que hacer coridiano. En los niveles y acritudes de vida de muchas familias, en el consumo familiar, en el mercado de trabajo, en las transf ormaciones de las tradiciones y formas de vida de algunas poblaciones, $y$ en otros aspectos del comportamiento social.

Por otra parte, debe destacarse el hecho que así como en el pasado los altos precios del café en el mercado internacional promovían "buenos gobiernos", dadas las posibilidades en el gasto público y en los ingresos de los exportadores de café, favorecian la actividad económica en general. Ac-
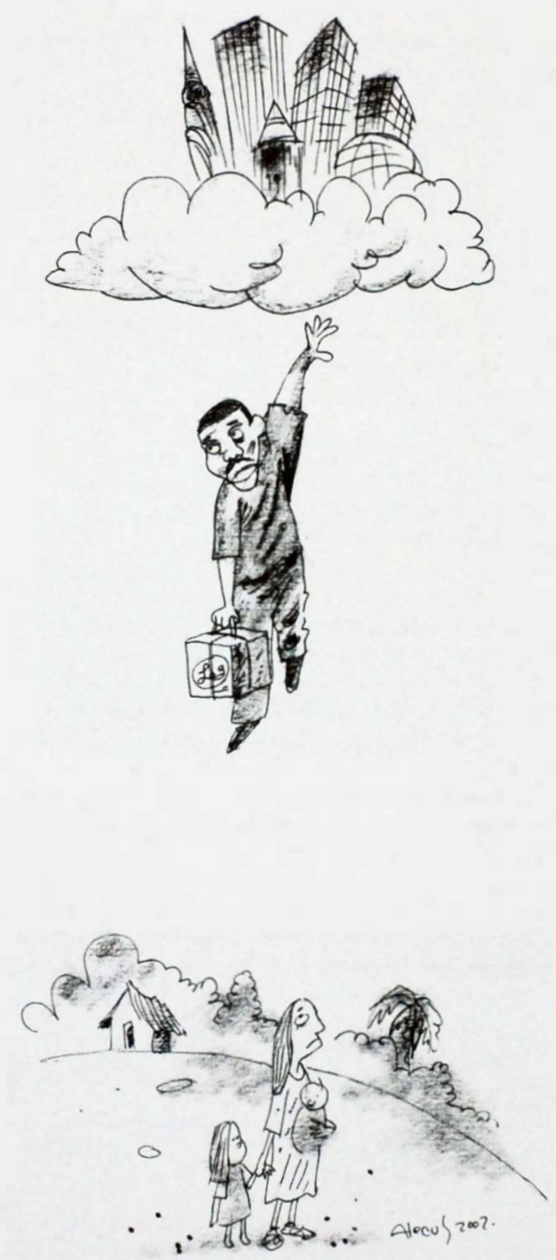

Febrero-Marzo 2002, $\mathrm{N}^{\circ} .23$ 
tualmente la trascendencia de las remesas en la vida nacional, beneficia la economfa salvadoreña, tanto por su cuantía como por la peculiar constancia en su ingreso.

Los argumentos expuestos anteriormente justifican la necesidad de hacer un estudio a profundidad de esta realidad. Hay una serie de preguntas que requieren ser explicadas en relación con este tema, por ejemplo ¿Cuánto tiempo más puede esperarse el ingreso significativo de estos recursos? ¿Cuáles son las acritudes que adoptan los sectores de población que no tienen necesidad de trabajar para vivir? ¿Se ha producido o no un consumismo que se encuentra disociado con el nivel y capacidad de las familias recipendarias de la ayuda familiar? ¿Los ingresos recibidos sirven para gastos de vida o se urilizan para inversiones y acumulaciones de capital?

Hay estudios de casos sobre poblaciones en que residen familias beneficiarias que muestran aspectos particulares sobre el fenómeno de las remesas. A nivel macroeconómico, el énfasis ha sido señalar las bondades en materia de equilibrio del sector ex-
«Migrar no es delito, delito es lo que causa la migración y nadie es ilegal donde quiera que viva, porque la dignidad y los derechos de los migrantes no tiene fronteras y nada puede detener el sueño de los migrantes».

Misioneros Scalabrinianos en Guatemala. terno y la estabilidad económica de manera general; recientes estudios regionales se han orientado a la discusión sobre opciones de uso productivo que tienen estos recursos.

Se pretende hacer un recorrido sobre el fenómeno migratorio a fin de explorar elementos históricos comunes con el presente, y destacar la osadía y las razones de la movilidad humana, en aras de contribuir a la sensibilización social sobre esa realidad; buscamos descubrir novedades o profundizar y fundamentar las verdades ya conocidas sobre el impacto que tienen las remesas en el campo nacional, con el objetivo final de resaltar la nueva dependencia que reviste la economia y la deuda ética que surge con los ahora llamados hermanos lejanos.

\section{Migración en búsqueda de la esperanza}

$\mathrm{L}$ a emigración es una vieja costumbre que tenemos los humanos para sobrevivir, la dirección de las corrientes migratorias cambian en el tiempo e incluso se invierten: siglo y medio atrás los Estados Unidos ocuparon territorio mexicano y ahora son los mexicanos quienes desean arribar pacíficamente a suclo norteamericano.

A partir de la segunda mitad del siglo XIX hasta la primera guerra mundial, con el estímulo de políticas migratorias abiertamente favorables o por lo menos tolerables, cerca de cincuenta millones de personas mayormente europeos se trasladaron hacia los nuevos mundos de América y Oceania, para satisfacer la creciente demanda de mano de obra que generaba el fuerte dinamismo económico de los países que acogieron aquellas masas de hombres y mujeres.

Dichos movimientos fueron voluntarios y tuvieron el visto bueno de los Gobiernos, y serían el referente de una de las aspiraciones dentro del actual fenómeno de globalización para las llamadas naciones del sur: la libre movilidad de la mano de obra, que ya gozan los habitantes nacionales dentro de los paises que conforman la Unión Europea.

En cuantia, existe como precedente los grandes contingentes de esclavos que obligada y violentamente salieron del continente africano para ser explotados brutalmente en la floreciente actividad agrícola del Sur de Estados Unidos', y de países caribeños, algunos centroamericanos y otros suramericanos.

La validez y la legalidad, por ser autorizados por la Corona, para los ejecutores de esos traslados masivos, obviamente resultaba ilegítima y deplorable para los pucblos que suf rieron la marcha forzada y despiadada que acompañó la salida de aquellos desafortunados y futuros esclavos de procedencia africana. Entre otros ejemplos de migración involuntaria se tiene el destierro que enf rentaron los judios (siglo XV) y moriscos (siglo XVII) en España; en el siglo $X X$, la expulsión y desplazamiento por causas políticas que afectaron a los judios con el régimen nazi durante la segunda guerra mundial y en el plano de las deportaciones, resalta "el movimiento de un un millón de griegos desde Asia Menor a Grecia y de 300 mil turcos en dirección opuesta"2, a causa del Tratado de Lausana de 1923.

Es ampliamente conocido que la primera porencia económica del mundo tiene su origen y base en la migración, principalmente extracontinental con una amplia y variada diversidad érnica y racial. Por un largo periodo dicho país mantuvo la aspiración de convertirse en una nación de naciones, fenómeno denominado crisol fundidor ${ }^{3}$, como indicativo que las diferencias culturales de la heterogénea población llegarían a formar una sola visión americana sin que necesariamente tuviese que desaparecer aquella diversidad. Muy a pesar de este sueño para las elites dominantes, los nativos sobrevivientes se convirtieron en americanos involuntarios.

Durante la segunda mitad del siglo XIX se produjo una gran oleada de inmigrantes nuevos ${ }^{4}$ a la región norte del 
continente americano. Inicialmente fue de irlandeses, muchos con previo asentamiento en Inglaterra, luego italianos, polacos, rusos, gente de la Europa central y meridional, japoneses y chinos; es decir, que el grueso provenia de las ahora poderosas naciones del planeta por su riqueza, pero que hace dos siglos eran regiones pobres $y$ azotadas por los devastadores efectos de continuas guerras, incluso con la presencia de hambrunas; situación que hizo declinar los movimientos intracontinentales en Europa muy comunes en esaépoca. a excepción de Alemania que mantuvo el interés como destino para polacos, rusos $\mathrm{c}$ italianos, enere otros, quienes llegaron a suplir la emigración hacia América de los propios alemanes. Se estima que "en 1910 el Imperio germático, en su pleno apogeo, mantenía un millón 250 mil inmigrados curopeos permanentes"s.

En el pasado como en el presente, las cifras de inmigración hacia Estados Unidos son elocuentes sobre el enorme contingente de trabajadores en búsqueda de oportunidades. Entre 1880 y 1900 arribaron cerca de 10 millones; de 1901 a 1910 fueron 9 millones; casi 6 millones entre 1911 a 1920 y 4 millones en los años veinte; descendiendo a sólo 528 mil durante los años treinta (alrededor de 50 mil anuales) ${ }^{6}$. Por el uso intensivo de esta fuente de mano de obra se estimuló la migración de población blanca y la proporción de raza negra se redujo a la mitad ( 10 por ciento) a finales del siglo XIX. El citado Censo de 1790 informó que la población alcanzaba los 4 millones", de manera que en los siguientes 125 años la migración septuplicó la población de aquella nación. Otro referente dentro del continente americano en cuantía importante, si bien a distancia, se ubica en la emigración a Brasil, Uruguay y Argentina con cerca de 12 millones $^{8}$.

Dado el proceso expansionista en la actividad productiva y posteriormente geográfica hacia el territorio oeste, la inmigración fue vista como cosa favorable, incluso en el periodo que operaron los cupos. Sin embargo, gradualmente fueron cimentándose actitudes y pasiones xenofóbicas en los primeros inmigrantes $y$ sus descendientes, ahora ciudadanos prósperos, quienes veían en los nuevos inmigrantes a seres indeseables, peligrosamente pobres, competidores de oportunidades, y/o enemigos religiosos.

Con la incesante inmigración se fue gestando un abarrotamiento del mercado de trabajo que en unión al aumento de la productividad que derivó el progreso tecnológico, suscitó un creciente cjército de reserva de los trabajadores. Tal situación es la base y explica porqué "la vida del trabajador en el siglo XIX no era fácil ni mucho menos. Aun en las buenas épocas, los salarios er an bajos, los horarios muy largos y las condiciones de trabajo peligrosas"". Como resultado lógico el inmigrante ocupaba el peldaño más bajo en la escala social y era el efecto de una fuerte discriminación por motivos de origen étnico, religión, acento y particularmente color de la piel.
Los primeros extranjeros que causaron problemas resultaron ser los que arribaron con posterioridad a los colonos ingleses: los irlandeses, quienes adenás de ser pobres arrastraban una fe religiosa católica, por lo que resultaba dif icil asimilarlos. El siguiente grupo nacional de inmigrantes que propició recelo fue el de origen chino, ya que a pesar de que convivían y cooperaban pacíficamente conservaban una tmanera de vivir culturalmente diferente, que atentaba contra el crisol fundidor.

Las crecientes protestas de la población blanca, como grupo étnico dominante, contra la libre entrada de extranjeros llegaron a tener eco en las autoridades. Hacia 1882. se emitió la primera ley anti-inmigrante contra los chinos. La otrora extranjeros, en muestra de cínico desprecio, alternativo al desembarco en Manhattan, destinaron la Isla de Ellis como punto de llegada a los inmigrantes en 1892; a los nuevos arribistas y futuros ciudadanos norteamericanos, como bienvenida les esperaban el desembarcar una especie de jaulas en su paso por aquella estación de inmigración, a fin de que fueran objeto de revisión y confirmación de que se cumplian los cupos y demás restricciones migratorias impuestas crecientemente desde 1882.

Por otra parte, "en 1907 el Presidente Theodore Roosevelt respondió a los temores de la mano de obra estadounidense ante la competencia, convenciendo al gobierno de Japón de que suspendiera en forma temporal la emigración de sus trabajadores a los Estados Unidos" ${ }^{10}$; en una suerte de pacto de caballeros a fin de evitar el insulto que supondria una restricción propiamente legal.

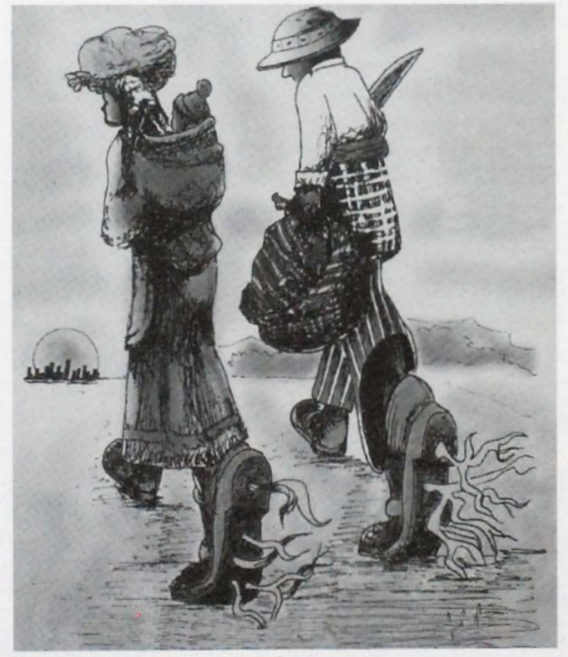

Foto: Thirza Ruballo, afiche médico sin fronteras 
Fue en 1924, que se aprobó una ley permanente de inmigración (vigente hasta 1965), con la que definitivamente se pretendió (y nunca se logró) fijar por cupos la composición étnica de la nación. El antecedente que encendió las pasiones xenof óbicas y justificaron detener la libre inmigración radica en el temor que suscitó la revolución rusa y el peligro de una potencial expansión hacia el resto del mundo con la exportación de bolcheviques; además que el mercado de trabajo se había saturado.

Los pujantes migratorios retrocedieron por las restricciones legales y mayormente por la desesperanza que propició la gran depresión en los años treinta. No obstante, el descenso fue pasajero y el dinamismo migratorio luego cobró nuevos bríos, iniciando con los miles de refugiados que arrastró la segunda guerra mundial.

Para tener una idea sobre la dinámica e importancia en el tiempo de los nuevos habitantes en Estados Unidos según su origen, entre el periodo 1850-1940, se ilustra históricamente la estructura poblacional según origen nacional.

Se destaca la infima connotación de la población de origen latino, la que contrasta con la situación a principios del presente siglo, en la que este sectorpoblacional (cerca de 30 millones, 10 por ciento del total) tiene en perspecriva, para un lapso menor a 30 años, convercirse en la principal minoria de Estados Unidos, incluso arriba de los habitantes africoamericanos; y que el idioma castellano posiblemente se convierta en la segunda lengua, entre los angloparlantes norteamericanos; mas que por el número de hispanoparlantes que habitan en Estados Unidos, por la rica literatura producida".

La movilidad poblacional ha sufrido cambios a lo largo del tiempo. Además de la migración a ultramar destaca la intracontinental en Europa, como medio de escape a la miseria y con la esperanza de hacer fortuna o simplemente como solución a la sobre población, guerras y epidemias. Irlanda fuc uno de los principales exportadores de nacionales al continente. Se conoce que a mediados del siglo XIX se estacionaron 600 mil irlandeses en Gran Bretaña, aunque para un grupo considerable ese paso fue una residencia temporal ya que luego transitaron hacia Norte América.

Los éxodos rurales y los Estados fronterizos bajo el estimulo que ocasionó el auge de las manufacturas en algunos paises curopeos, muestran similitudes a la experiencia latinoamericana del siglo $X X$, con el proceso desarrollista impul sado dur ante el segundo y tercer cuarto del siglo pasado, canalizando a través de la sustitución de importaciones como modelo de crecimiento económico y acumulación de capital; proceso que multiplicó las fuentes de empleo y generó oporrunidades de mejores ingresos en las ciudades.
Particularmente aquellas en las que se conceneró el desarrollo industrial; estimulando proliferas migraciones internas; las de estadía permanente (provenientes de áreas rurales y ciudades con bajo perfil productivo) potenciaron la formación de ciudades con alta densidad, en los lugares que se agruparon las fábricas, alojamientos comerciales y otro tipo de servicios.

La tradicional migración campo - ciudad de la región latinoamericana se ha combinado ( $y$ en muchos casos sustituido ) con la migración entre paises: principalmente desde las naciones pobres hacia las naciones ricas. En la actualidad mayormente la tierra de la promesa y de la esperanza nuevamente se sitúa fuera de las fronteras y distante dando paso al llamado sueño americano (o curopeo para otras regiones del planeta según cercanias del continente que se parte).

\section{Movimientos migratorios recientes}

I movilidad poblacional hacia el exterior, si bien Cen cuantía relativamente menor que hace un siglo, ha recobrado auge en el último cuarto de siglo. Estos movimientos migratorios coinciden con el periodo de recesión mundial y la crisis de la deuda externa, y constituyen uno de los fenómenos característicos de los pasados años ochenta y noventa, con énfasis el proveniente de los paises subdesarrollados. Tales movimientos son de naturaleza política como económica, destacándose los enormes desplazamientos transfronterizos de personas indocumentadas.

Algunas estimaciones ubican entre 4 a 7 millones el total de emigración de contrabando a lo largo del planeta ${ }^{12}$, dimensión que por momentos cobra importancia xenof óbica en el discurso oficial y de algunos sectores sociales dentro de lospaises receptores: en ocasiones por coyunturas electorales en los que se vende la idea que esos paises son vícrimas, de una especie de invasión, por las avalanchas masivas de "menesterosos indeseables". Y en otras, por los supuestos problemas socioeconómicos que al Estado acarrea su presencia y el desplazamiento de puestos de trabajo para los nacionales, situación que invita erradamente a combatir y frenar la migración ilegal con rodo el peso de la ley c instrumentos represivos que rienen disponibles los gobiernos de turno, convirtiendo al inmigrante en chivo expiatorio de los problemas que sufre el pais al que arriban; y quienes aparecen como baluarte contra la amenaza de la inmigración ganan votos electorales y/o consolidan posiciones politicas en los sectores que los apadrinan.

Durante la época reciente se calcula que 13 millones de latinoamericanos han emigradoa Estados Unidos y alrededor de 2 millones viven en algún pais dentro de la región ${ }^{13}$. 


\section{Migración y remesas familiares; nueva dependencia de la economía}

Según las Naciones Unidas a escala planetaria se cuantifica en 140 millones las personas que viven en países que no son en el que nacicron 14

Para el caso salvadoreño se estima que entre una sexta y una quinta parte de la población vive en los Estados Unidos ${ }^{15}$. Los datos difieren según la fuente consultada. La principal fuente of icial son loscensos nortcamericanos que para 1990 , informan que residian en aquel país cerca de medio millón de origen salvadoreño (465 mil 460), quintuplicado la registrada por el censo de 1980 , de $94 \mathrm{mil} \mathrm{447.} \mathrm{Tales} \mathrm{cif} \mathrm{ras}$ se consideran conservadoras, a pesar de que se pretende registrar en su totalidad a los inmigrantes, no importando su estatus legal, hay quienes por el temor a ser deportados se esconden y no son incorporados en las estadísticas, sin que se conozcan que proporción representan quienes quedan fuera del cómputo.

El inventario de las migraciones de compatriotas es limitado e impreciso, particularmente por el carácter clandestino que mayormente matiza en la actualidad la salida de salvadoreños, lo que da paso a calificaciones como "estadísticas de los incontables". Por eso hay disponible una variada gama de estimaciones, cuyas cifras oscilan entre 1.2 a 2.5 millones de salvadoreños. No se conoce a ciencia cierta cual es la cifra real o más próxima al total de compatriotas inmigrantes que viven efectivamente en el pais del Norte.

Pero existe coincidencia en mostrar a El Salvador como el principal exportador de mano de obra: las tasas de emigración ${ }^{16}$ indican que nuestro pais supera notablemente al resto de Centroamérica. Con reservas mencionamos que las cif ras conocidas refieren que sólo entre 1989 (año de la of ensiva) y 1990 salieron del país arriba de $140 \mathrm{mil}$ inmigrantes, y que luego de los Acuerdos de Paz declinó la salida de compatriotas hasta mantenerse en alrededor de 25 mil anual. Pareciera que hay un compás de espera para que cerca de 1 millón de salvadoreños aspirantes a inmigrantes hagan realidad su deseo y se lancen a la aventura por el sueño americano. Además, se percibe un incremento del flujo migratorio en tránsito de países sudamericanos y asiáticos a El Salvador, que ocupan el territorio como puente en ruta hacia el norte.

Entre las autoridades gubernamentales de los paises de destino y analistas más cercanos a la población extranjera en condición de ilegalidad, obviamente no existe una visión común sobre el diagnóstico y valoración del aporte económico y de diversa índole, que crean los extranjeros indocumentados; pero sí hay un consenso en calificar que la migración ilegal constituye un pujante y lucrativo negocio millonario: entre 7 a 12 millones de dólares se calcula el ingresoanual que perciben los traficantes de ilegales alrededor del mundo, con tarifas de hasta 40 mil dólares ${ }^{17}$ por llevar a una persona a Estados Unidos. Mientras mayor sea la distancia a que se encuentre el pais de origen o la rigidez de las restricciones migratorias mayor es el precio que se cobra a los aspirantes a emigrar.

\section{La migración es un destino inevitable}

Terdaderamente la razón sobre lo infructuoso que ha sido, y es, obedece a que los desplazamientos poblacionales no son una suerte de "espasmo colectivo" descontrolado abandonados a la irracionalidad, pues por el contrario, a pesar de los escenarios, por lo general, clandestinos en que se fraguan, su impulso radica en la pública y mundialmente informada creciente demanda de mano de obra, mayormente no calificada, de los principales países occidentales prósperos.

Para la región latinoamericana y en particular para nuestro país, el destino ordinario por obvias razones es los Estados Unidos. Otros destinos cuantitativamente importantes han surgido a través de programas migratorios que favorecen y estimulan el traslado desde nuestros países hacia algunas naciones desarrolladas $y$ a veces del tercer mundo, en condiciones notablemente atractivas y con un relativo inmejorable estatus legal. Nos referimos, por ejemplo, a la experiencia salvadoreña de los años ochenta con Canadá y Australia, paises que tenían interés en expandir su población, y que para garantizar que quienes emigraran no volvieran a sus lugares de partida, seleccionaban, principalmente, a personas con algún tipo de persecución política. También recordamos en los años setenta la migración temporal que se dirigió a un pais del medio oriente para la construcción de una ciudad. Los obreros que partieron a Estados Unidos para trabajar en la industria bélica durante la segunda guerra mundial; y los que emigraron para trabajar en la construcción del canal de Panamá.

La pobreza no es propiedad exclusiva de los países del sur, pero la dif erencia es que aquí es mayoritaria. El informe sobre el Desarrollo Mundial. 2000/2001, señala que "Nuestro mundo se caracteriza por una gran pobreza en medio de la abundancia... mientras que en los países ricos menos del 5 por ciento de todos los niños menores de cinco años sufren de mal nutrición, en las naciones pobres la proporción es de hasta el 50 por ciento"18

Se ha dicho que "la pobreza es degradante, deprimente y deshumanizante, .... (y que) cuando coexiste con la prosperidad de una minoría tanto dentro comoentre países sencillamente resulta obscena ${ }^{19}$ ". Ninguna nación se escapa. Pero cuando la mayoría de los pobres en el Sur puesto que "El ingreso promedio en los 20 países más ricos es 37 veces mayor que el de las 20 naciones más pobres" ${ }^{20}$, huir en búsqueda del progreso y la superación no puede tener otro horizonte que el norte. 
La desigual distribución de la riqueza de ingresos y oportunidades dentro de los países subdesarrollados se reproduce entre las naciones. Uno de los factores explicativos, segín lo afirma Amartya Sen. Premio Novel de Economia 1998, en buena medida radica en la creciente brecha tecnológica que muestran los diversos paises. Por efecto directo del rezago tecnológico se ha provocado que incluso en actividades económicas consideradas como primarias, caso de los alimentos, se están gener ando abismos infranqueables entre paises que producen casi como hace dos siglos en contraste al aceleradoavance en productividad que presenta Europa, Japón o Estados Unidos ${ }^{21}$

Se sabe que "la economía americana viene mostrando una notable capacidad para crear nuevos puestos de trabajo, a un ritmo de casi dos millones de empleos netos por año"22, consecuencia de los exitosos resultados obtenidos en materia de gestión presupuestaria, significativo incremento de las

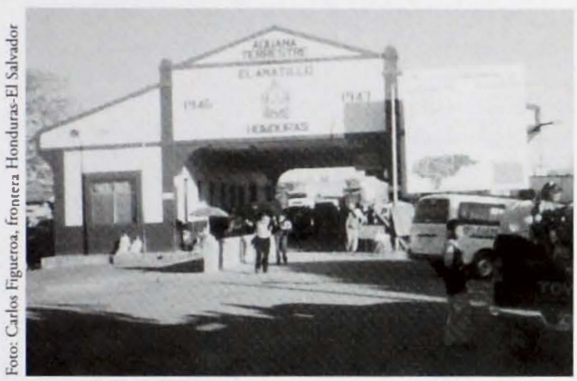

inversiones e innovaciones tecnológicas que han provocado alzas en la productividad, descenso del desempleo y el alza de las cotizaciones bursátiles; de manera que los emigrantes, si bien no van con el pan garantizado bajo la manga por solo llegar a su destino, existe cierta seguridad que van a encontrar trabajo pronto.

Con aquella montaña de oportunidades es imposible detener a quienes se aventur an por el sueño dorado, máxime que de ese toral de empleos que se están creando en la economia norteamericana, 60 por ciento corresponde a servicios y que el aumento de empleos de baja calificación en cuanto son trabajos que no requieren mayor formación (a la que por lo general acceden los indocumentados), es superior al aumento de los nuevos empleos de alta y media calificación: escenario que contrasta con las esperanzas y promesas de un mejor futuro en oportunidades e ingresos que traerá algún dia los "insoslayables" programas de ajuste estructural que se aplican en los países de origen. Oportunidades concretas por las cuales competir en el norte, contra oportunidades promeridas en el sur que son inciertas.
Por ello, se dirá que a los países receptores llegarán los inmigrantes que tienen que ir $y$ a pesar de las dificultades de inserción a la sociedad, sea cual sea la legislación discriminatoria y opresiva vigente o que pudiera aprobarse, no importa que año con año se incrementen los efectivos policiales que realizan las tareas de contención de la migración ilegal, a quienes se les provee de los últimos recursos tecnológicos de apoyo para sus acciones de represión del contrabando de indocumentados ${ }^{23}$. $\mathrm{O}$ que las ciudades principales puntos de localización de los inmigrantes muestren panoramas de sobrevivencia penosa, racismo y otras secuelas, que claramente les recuerden y los hacen sentir que son no solo extranjeros sino quizá hasta "indeseables" ${ }^{\text {". }}$. A pesar de que obtienen menores ingresos en comparación con los residentes legales conduce a que muchos indocumentados se "asilen" en los barrios bajos, que detentan características a veces a distancia y en ocasiones similares a ciertos lugares de origen de los inmigrantes: mugre, oscuridad y hacinamiento.

Incluso debe mencionarse que los nuevos empleos en expansión por el fuente y sostenido dinamismo que muestra la economía norteamericana, en las ramas del sector terciario que ordinariamente aplican los indocumentados, no observan mejorias salariales, en vista de que la productividad del trabajo ha aumentado muy lentamente al grado que prácticamente puede calificarse de estancada; en contraste con las ramas del sector servicios que requieren mayor cualificación de la mano de obra y que por el incremento del stock de capital físico que han experimentado, al elevarse los coeficientes de capital-trabajo y capital-producto, han sido beneficiadas con sensibles alzas en las remuneraciones.

Sin embargo, las diferencias salariales ente los paises receptores $y$ los de origen siguen mantenićndose a niveles ostensibles; por lo que inferiores remuneraciones del factor trabajo y baja creación de nuevosempleos en nuestros paises son los detonantes que impulsan a emigrar. A esto hay que agregar que la insuficiente creación de oportunidades de trabajo tiene el agravante de caracterizarse por una vasta proliferación de trabajos precarios. Sobre el particular el Secretario Ejecutivo de la CEPAL ha señalado:

"En los años noventa existen dos tendencias particularmente preocupantes en el mercado laboral, que generan presiones adicionales hacia la desigualdad. La primera es la disparidad creciente entre las remuneraciones de los trabajadores más calificados y las de aquellos que cuentan con menores niveles de calificación.... La segunda es la escasa generación de em pleo formal y el consecuente deterioro de la calidad de los empleos. De acuerdo con las estimaciones de la Organización Internacional del Trabajo (OIT), poco más de ocho de cada diez puestos de trabajo creados en los años noventa corresponde a ocu paciones de ba ja calidad en el sector informal"'s. 
Fots: Thiras Ruballu, los envigesnies enf rentan cuslquier riesgo por lograr ste propessitos.

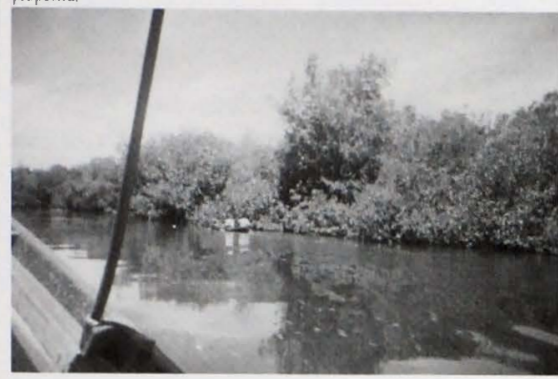

Tales condiciones han promovido una ampliación de las desigualdades internas que observan nuestros países, que ya en el pasado eran preocupantes en términos de estabilidad social: para la década de los años ochenta se calculó que "en El Salvador, el trabajador más educado ganaba 71.2 por ciento más que el trabajador menos educado, mientras que en los Estados Unidos era solo el 16.3 por ciento"26 la dif erencia.

En el caso salvadoreño los mayores resultados en generación de empleo en los tíltimos diez años, han radicado en la maquila, que es una industria intensiva en mano de obra, con organización productiva y exigencias de trabajo desgastante y salarios nada envidiables para el resto del mercado de trabajo, pero que significan oportunidades de ingreso al final de cuentas. No obstante, es desolador recordar recientes propuestas de bajar los salarios mínimos a $\$ 700$ parazonas como Chalatenango, en aras de atracr e incentivar nuevas inversiones en este sector productivo, cuando ya el salario minimo vigente resulta trágico. Este tipo de ideas que pretende influir y direccionar la politica económica son parte del menú de razones que explican porque, cerca de un millón de salvadoreños pretenden emigrar hacia nuevos derroteros ${ }^{27}$. En cambio, sociedades calificadas como modesta pero humanamente exitosas como la costarricense que si bien tienen un Producto Interno Bruto y Producto Percapita inferiores a otras naciones en el sur del continente americano, dado los niveles de equidad y servicios públicos, reflejo de la aspiración de una economía con rostro humano en materia de distribución de ingresos y otros que al final vienen a generar una buena calidad y mayor esperanza de vida para sus conciudadanos, en vez de ser exportadores de mano de obra, constituyen modestos puntos de llegada para emigrantes de la región.

Contrario a las perspectivas desfavorables que anuncia el sector maquilero de la economia salvadoreña como requisito para relanzar el crecimiento, el horizonte para quienes desean y aspiran a emigrar al norte les revela una fuerte of erta de nuevos trabajos cada año, y que "la renta media de las familias crece con regularidad desde 1993, y en 1997 el salario medio comenzó a aumentar por primera vez en un cuarto de siglo... (y a pesar que) las diferencias de ingresos han seguido aumentando, los salarios bajos también subieron en los Estados Unidos. Las cifras del paro están en su nivel más bajo en el ámbito nacional desde 1969, al igual que la pobreza, inferior en 1999 a lo que fue en varias décadas" 28

Sin pretender caer en concepciones absolutistas mas si destacar los elementos capitales en la explicación del fenómeno, somos de la idea que definitivamente es la estructura y evolución del mercado de trabajo de la gran nación en confrontación con las magras posibilidades de progreso en nuestros paises, la raíz motriz de los flujos de inmigrantes indocumentados. Como señala La CEPAL "cl crecimiento económico y los esfuerzos por controlar la inflación y equilibrar las cuentas fiscales y comerciales registraron progreso en muchos lugares, pero la lucha contra el desempleo registró derrota tras derrota"29. Por lo tanto, la migración es un fenómeno imparable pues los factores de la producción suclen movilizarse y acomodarse con independencia a las concepciones económicas de los gobiernos, y responden más a las expecrativas de rendimiento observables en cada espacio geográfico: aqui no hay distinción entre el factor trabajo y el factor capital. O como se ha dicho: "no cabe duda que ajena a los discursos teóricos de los entendidos, la economía busca sus mecanismos compensatorios para el diario vivir" ${ }^{30}$.

\section{Condicionantes de la migración}

D esulta fácilmente comprensible que la población Rinmigrante de Alemania, Francia y Bélgica, comparada con el total de cada país, seacntre 6.7 a 7.5 veces la que vive en España" 31 , merced al menor desarrollo alcanzado por este último país y en consecuencia menor atractivo como destino al ser menores las oportunidades. También durante los años treinta la emigración hacia Estados Unidos descendió a niveles insignificantes en comparación a periodos anteriores, pues las consecuencias de la gran depresión volvicron poco atractivo al pais; y se estima que aun hubiese sido menor si no se produce el ascenso de Hirler al poder.

Indudablemente en la actualidad la evolución económica es radicalmente distinta a aquella época y por consiguiente encaramos un poderoso estimulo a la movilidad.

Particularmente el trabajo diríamos que es el factor de la producción más independiente, máxime cuando hay poco que perder, ya que incluso ni siquiera exige para su desplazamiento o relocalización seguridad juridica o seguridad contra la delincuencia, como la requiere la inversión extranjera que invocamos ansiosamente, y la que grandes esfuerzos ha morivado para la asignación de recursos 
en los presupuestos públicos, y de otros múltiples incentivos fiscales en los paises latinoamericanos, para satisfacer sus exigencias y volver atractivo al ser punto de destino.

Al contrario, la movilidad laboral resulta barata para los paises receptores que se beneficien de las inversiones en capital humano que realizaron las naciones de origen; para los primeros lo dispendioso son los esfuer zos relativamente ineficaces para frenarla. Por cada cinco que detengan las patrullas fronterizas norteamericanas se cuela un indocumentado, viene a ser un paragón de la práctica cultural que existia en nuestros campesinos, de procrear muchos hijos pues de esa manera se compensaba la pérdida futura de mano de obra por la muerte de algunos de ellos que ordinariamente ocurria merced a las pobres condiciones de vida que arrastraban en sus hogares.

Lo realmente oneroso, por lo tanto, viene a ser para el migrante indocumentado, los costos financieros de la hazaña que le distraerán significativos recursos de los ingresos que después de llegar tendrá que pagar por el viaje: ya sea a los familiares que le antecedieron en la aventura o a quienes le prestaron los fondos para la travesia en su lugar de origen.

Quienes emigran con recursos propios, por lo menos en el caso salvadoreño, a partir de los años ochenta, representan una minoria, para quienes incluso no existen riesgos y los gastos del viaje son relativamente bajos ya que de ordinario transitan con visa; y son pertenecientes a la clase alta y media, quienes en el pasado prácticamente tenian reservado este privilegio, con estadias de carácter temporal o permanente en el lugar de destino.

Sin que valga su condición o estatus legal, la migración laboral resulta ser el complemento de trabajadores de los diversos sistemas productivos, no importando tampoco si este es de un pais del primer o tercer mundo: por ejemplo, para la economia dominicana, los brazeros haitianos son un

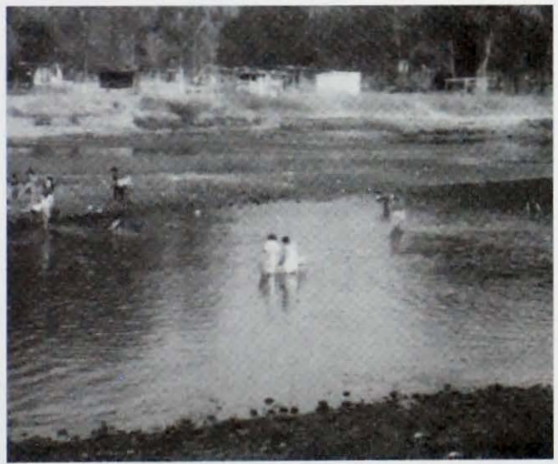

Foto: Thirza Ruballo, muchos mueren producto de los accidentes en los pasos

Entorho frondSSN: 2218-3345 bastión importante en muchas tareas que abarcan a los sectores agrícolas (con énf asis en la ardua corta de la caña de azúcar), servicios de limpieza en empresas y domésticos en los hogares. La razón de su demanda viene a ser una reproducción de lo que sucede en la nación norteamericana: el estimulo a la migración radica en las peores condiciones de pobreza que abaten a los haitianos y las tareas a que se dedican son aquellas que los "merengueros" desprecian.

Por lo tanto, compartimos la creencia que la migración es un destino inevitable mas no una pesada herencia. El fenómeno es planetario y a pesar que el origen y lugar de llegada más atractivo por los rendimientos potenciales sean los desplazamientos Sur-Norte, no son exclusivos. También se producen importantes movimientos entre los paises pobres, transitorios, estacionales y permanentes según la estadia:

- En el estado de Chiapas (México) el grueso de la mano de obra utilizada en la recolección del café es de origen guatemalteca (mayormente residentes ilegales);

- Peruanos emigran a Chile para trabajar en lu industria de la construcción, como parte de la diáspora peruana que se estima en 1,9 millones $^{32}$,

- Bolivianos prestan sus servicios en las estancias argentinas, y no obstante ser un pais pobre, Bolivia es un lugar de destino para peruanos;

- Muchos compatriotas salvadoreños se unian a la fueras de trabajo de los nicaragïenses para recolectar los cultivos de sus tierras, particularmente algodón: ciclicamente se les abrian las puertas en los periodos de cosecha para repatriarlos después que habian cumplido su cometido. También grandes contingentes de salvadoreños (se estiman en 300 mil) se trasladaron hacia Honduras, y muchos fueron repatriados (alrededor de 200 mil), por la represión que desato la guerra de 1969.

En el presente, la agricultura costarricense se beneficia de mano de obra nicaragïense;

- La circulación de mujeres centroamericanas dentro de la región para trabajar en prostitución: salvadoreñas a Guatemala y de Nicaragua a El Salvador y Costa Rica.

- Otro caso peculiar por las derivaciones sociales resulto ser la partida de miles de mujeres marroquies a Libia en la deiada de los ochenta: "llegaron.... para convertirse en la clase de las trabajadoras de servicios... Muchas no obstance, se dedicaron a la prostitución, un servicio anteriormente con poca oferta. Existe el rumor muy generalizado de que esa tendencia five alentada por el gobierno en un esfuerzo por aliviar las frustraciones sexuales de la población masculina, sin poner en riesgo la virud de las mujeres 
locales... El tiro salió por la culata... Cuando las cosas se pusieron dificiles, las pobres mujeres libias se dieron cuenta de lo mucho que esas damas estabun ganando y siguieron su ejemplons, etc.

En suma, compartimos la idea que la migración hoy en día es un fenómeno fundamentalmente económico "en su origen y en su meta”, puesto que la causa más frecuente ${ }^{34}$ por la que salen de nuestros países grandes flujos de población económicamente activa (el grueso de las emigraciones), radica en los bajos ingresos que perciben los trabajadores en sus paises de origen y la falta de oportunidades de trabajo ${ }^{35}$. En conjunto, provocan y retroalimentan un marco de pobreza estructural, razón por la que comparimos que la migración resulta un destino inevitable en virtud de una especie de estrategia de supervivencia y/o progreso para familias pobres y otras en mejores condiciones económicas, pero que aspiran enriquecer su horizonte de vida. Otro ejemplo de que el reorema Hecksher - Ohlin no opera:

Sobre la base de este teorema, se pensaba que con el libre comercio y la vigencia de las ventajas comparativas como criterio de asignación de recursos en una economia, al provocar que los factores abund antes dejasen de serlo, se experimentaria una tendencia a la igualación de las remumeraciones de los factores de la producción. lo que vendria "a sustituir la necesidad que estos emigran en buisqueda de me jores rentabilidades. Pero esta premisa no se h a cumplido, a pesar de la floreciente globalización que reina en los uiltimos años: El comercio no ha cooperado en la equiparación del precio de los factores de la producción.

- Por el contrario, el descenso de los salarios viene a ser la herencia que se fortalece con la mundialización del mercado y a pertura externa. La práctica para atraer Inversiones $y$ promover com petitivid ad generalmente se ha promovido por Ia via fácil de la reducción de los sal arios reales (devaluación y/o atraso en ajustar los sal arios nominales segin el ritmo de la inflación), mas no por esfuerzos encaminados al aumento de la productividad a través de acciones de Investigación Desarrollo. El impacto ha sido general, de cuyo alcance no escapan las otras clases medias que ensancho el periodo desarrollista. En el caso de El Salvador como en otros paises, la solución o ajuste de la economia, más alli de un simple paliativo, se expresa en la migración hacia el sueño americano.

\section{No todo es fiesta, la adversidad acosa}

M uchos aventureros, mayormente los que transitan con guías conocidos como polleros, superada la hazaña y grandes sacrificios por la discriminación a que se ven sometidos, alcanzan el sueño dorado. Sin embargo, el "milagro" no les sobreviene a todos: se dice que sólo el 5 por ciento de quienes viajan sin guía logran llegar a la frontera norte de México.

Además, numerosas mujeres son introducidas cada año con fines de explotación sexual ${ }^{36}$ a países europeos y asiáticos; las que cruzan las fronteras conscientes de su destino o con engañosas promesas de trabajos legales, por lo general of reciéndoles la carnada de grandes ganancias, fácilmente vendible por la miseria en la que viven. La deplorable trata de mujeres comprende no solo la prostitución sino también los matrimonios forzados $y$ las adopciones falsas con fines de "disfrute" sexual. Así mismo, en la región existe el tráfico de menores con el móvil de explotación comercial sexual: de Centroamérica "se llevan y venden nin̄as como esclavas a los prostíbulos de Tapachula, a cien dólares cada una, y a niñas mexicanas las venden en Honduras, Brasil y Costa Rica a un precio equivalente" 3 ?

Otros, principalmente de origen asiático, tienen como destino una suerte de "moderno" esclavismo en actividades productivas que incluye torturas, a cuyo sometimiento son empujados por los elevados costos que les cobran los traficantes en quienes depositaron su futuro sueño dorado.

En ambas situaciones resulta casi imposible escapar del terror en que finaliza la aventura de la migración, dado el alto nivel de dependencia económica con los reclutadores o empleadores $y / o$ la circunstancia de fragilidad por indefensas condiciones de vida que rodean la explotación infantil y a los nuevos que arriban a los países occidentales: por la situación incierta, el no conocer el idioma ni los derechos que les asisten a pesar de sus estatus ilegal y el aislamiento social en que se desenvuelven máxime cuando no tienen familiares $^{38}$ o siquiera paisanos a donde llegar.

La suerte es trágica en otros casos: entre 1993 y 1998 fueron mil $185^{39}$ los muertos tratando de llegar a la "tierra prometida", y durante 1999, fallecieron $553^{40}$ indocumentados en el intento por cruzar la frontera estadounidense, incluyendo compatriotas. En el presente año murieron en Inglaterra 58 inmigrantes de la provincia de Fujian, lugar "donde es prácticamente un rito de iniciación para un joven partir al extranjero en busca de fortuna"41 ; y las cifras de lo que va del año 2000 en el azaroso viaje a Estados Unidos supera los 400 muertos. Se conoce que de los migrantes salvadoreños que salieron el primer semestre del 2000, son 20 quienes están desaparecidos, son alrededor de 6 mil la cifra acumulada desde 1990 a la fecha. La lista sería interminable de citar.

Para los inmigrantes centroamericanos el titánico cruce hacia la frontera estadounidense, en su paso por territorio mexicano, resulta un drama espeluznante con grandes peligros que exigen a los desafortunados viajeros alerta máxima contra los delincuentes, pandilleros, agentes de 
Migración y remesas familiares

migración y policía mexicana. La salvaguarda y medio de transporte más usado a partir de Tapachula es el tren carguero, del que frecuentemente tiene que bajarse (literalmentc: "aventarse" a los matorrales estando el ferrocarril en marcha), para escabullirse de los controles migratorios con que pretenden atraparlos y que están colocados en puntos fijos $y$ móviles durante el trayecto. "Adrenalina pura" es el vocablo apropiado que urilizó el periodista salvadoreño Alvaro López para calificar semejante osadía ${ }^{42}$, merced al estrćs que provocan las noches de vigilia e intentonas de abordar múltiples trenes, mantenićndose ileso de cualquier jugarreta

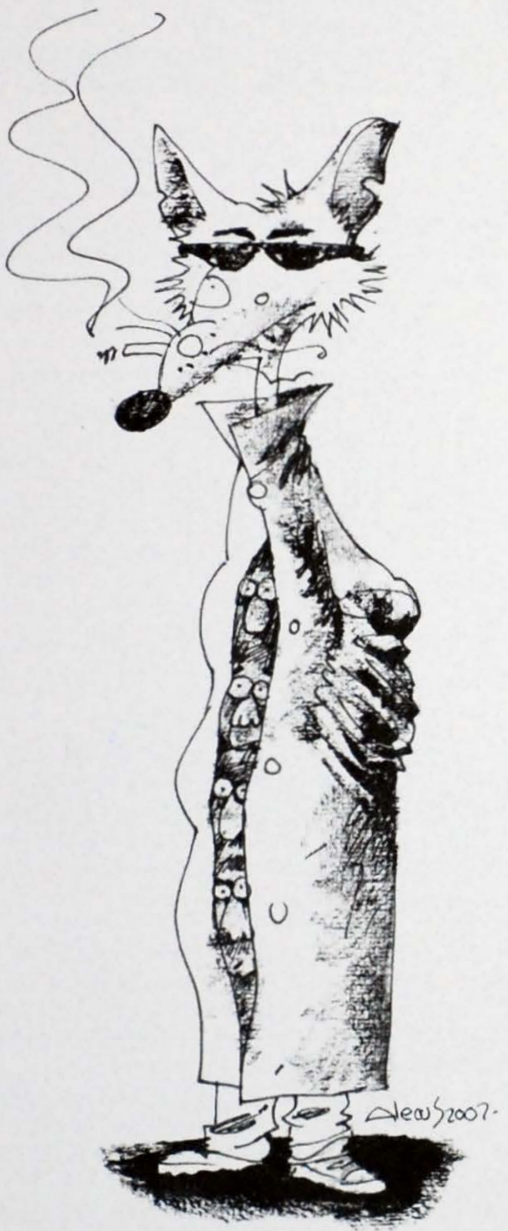

que el viaje suponga afrontar hasta lograr llegar a territorio fronterizo. Es común conocer de violaciones y torturas por bandas que se dedican asaltar a inmigrantes, delitos que quedan en la impunidad por la situación irregular de los afectados; y denuncias que las autoridades cuando los detienen les desvalijan los escasos recursos que lleva: ${ }^{43}$.

Las autoridades mexicanas han creado equipos de apoyo al inmigrante indocumentado, llamados Grupos Beta, encargados de patrullar las zonas fronterizas y demás lugares en que regularmente transitan los aspirantes a hermanos lejanos. Se entiende que prestan ayuda protegiendo de los delincuentes y abusos de autoridad, advierten sobre los riesgos y ocasionalmente brindan techo $y$ alimento al migrante. Paradójicamente, hay denuncias de robo a quienes están supuestos a proteger, peligro potencial que puede invitar a eludirlos como medida de prevención. Sin embargo, diríamos que algo es peor que nada ${ }^{40}$. y esta modalidad de ayuda constituye un esfuerzo del Gobierno mexicano en apoyo a una nueva culcura oficial de respeto a los derechos humanos de los migrantes.

En aras de controlar con mayor rigor la frontera común con México la patrulla fronteriza estadounidense ha incrementado en mil agentes su contingente desde 1994, alcanzando en la actualidad arriba de 9 mil el número de efectivos ${ }^{45}$. Adicional a los controles oficiales, en algunas zonas de la frontera estadounidense - mexicana han surgido grupos civiles de los ranchos fronterizos que acechan y hostigan a los inmigrantes (desde denunciarlos hasta cazarlos a tiros), cuyo nivel organizativo incluye la disposición de paginas web para consulta en Internet ${ }^{46}$. Mćxico tiene mas de 800 agentes dedicados a la contención de los desplazamientos migratorios ilegales en ruta al norte.

Para 1999 los resultados arrojan cif ras de 1.5 millones de detenidos en Estados Unidost" y 99 mil en México. Además, entre enero y noviembre del año 2000, las autoridades mexicanas han tenido y expulsado $33 \mathrm{mil} 683$ guatemaltecos, 22 mil 776 hondureños, 16 mil 204 salvadoreños y 930 nicaragüenscs ${ }^{4 R}$. Por su parte, los europeos han hecho lo propio, para contrarrestarla soleadas masivas de barcos en sus costas: solo las fuer zas de seguridad española han interceptado a 11 mil 500 personas en los primeros once meses del $2000^{49}$, detenciones que en su mayor parte han ocurrido en las costas de Tarifa, pues el estrecho de Gibraltar continua siendo para los af ricanos una de las principales puertas de entrada a Europa.

No obstante, todos los intentos han sido relativamente infructíferos: en Estados Unidos arriba de 275 mil nuevos indocumentados es el saldo de quienes intentaron y lograron completar la aventura migratoria en $1999^{40}$. Para Europa se estima que los extranjeros que llegaron en ese mismo año superan los $711 \mathrm{mil}^{\text {si }}$ 
Por lo tanto, a pesar de los riesgos y no obstante los grandes esfuerzos que los paises receptores llevan a cabo para detener la migración ilegal, ha sido incontrolable la llegada de extranjeros a los paises occidentales. De fondo persisten originarias condiciones de miseria que vuelven atractiva la aventura: la desesperación por salir de la pobreza motiva fructíf eros recursos de ingeniosidad para saltar los diversos escollos que puedan enfrentarse. Ahora hasta se ha creado La Guía del Perfecto Indocumentado (arriba citada), en cuya introducción reza:

"Cientos de mexicanos que buscan una vida mejor han muerto en su intento de llegar a Estados Unidos. Muchos logran cruzar y empiezan otra

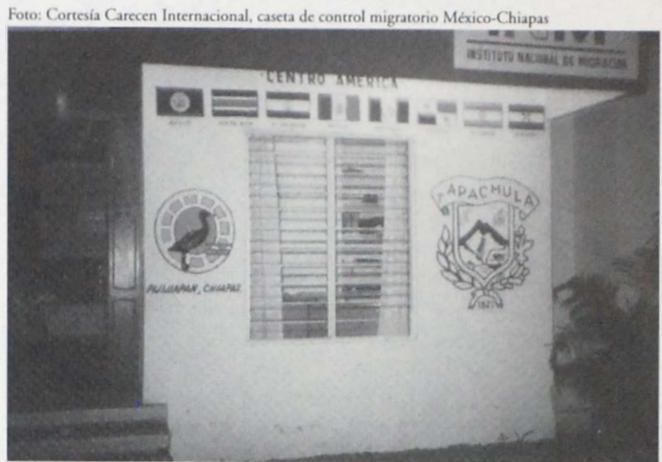
vida. De boca en boca van los conocimientos para ser indocumentado y no parecer en el intento, para encontrar papeles falsos y un trabajo, para buscar una vida mejor. Esta es una gufa para el aspirante a trabajador indocumentado en Estados Unidos".

Ante las violaciones a los derechos humanos $y$ las fatalidades que acosan a los inmigrantes, particularmente en la travesía al lugar de destino, han surgido voces promoviendo y exigiendo la creación de un procurador continental de migraciones que proteja sus derechos, vele porque no se comentan atropellos y estimule el diálogo entre los paises que enf rentan el problema.

\section{Xenofobia versus realidad}

T a existencia de desempleo y una dura comperitividad en el mercado de trabajo permite que los empresarios en búsqueda de bajos salarios, fácilmente encuentren trabajadores en los inmigrantes que por su situación irregular acepean poca paga, y en ocasiones por debajo del minimo legal. Efectivamente, para los paises receptores, la presencia de migración ilegal favorece la paga de menores salarios en los empresarios que los contratan, y la ocupación en actividades que los nacionales consideran de indescable estatus social. Como dato de referencia, se estima que un buen porcentaje de la población centroamericana que vive en Estados Unidos está indocumentada ${ }^{52}$.

Para la región curopea, cuyos habitantes crecieron en 0.3 por ciento durante 1999 , este fenómeno ha llegado a constituir la via de rejuvenecimiento de la población, ya que la baja tasa de natalidad acompañada de una mayor esperanza de vida que caracteriza la modernización les llevan a conformar sociedades vicjas ${ }^{33}$, pero que se están remozando con migrantes: el año pasado el 71.9 por ciento ${ }^{54} \mathrm{del}$ crecimiento poblacional obedece a los flujos emigrantes que han llegado a esa región.

Cuando las migraciones incluyen la salida de personas con cierto nivel de formación educativa, constituyen una especie de subsidio encubierto de los paises subdesarrollados a los paises más ricos (calculado en un monto superior a \$39 mil millones"s), ya que reducen los costos sociales en los países de destino y se ahorran lo que ya han gastado los paises de origen para quienes significa una pérdida importante en términos de fuga de cerebros (absoluta o relativa):

Se estima que un 10 por ciento de quienes emigran a nivel mundial han cursado estudios universitarios, lo que permite un significativo ahorro en educación y adiestramiento en los paises receptores ${ }^{36}$. Por ejemplo. se conoce las migraciones de cientificos que han suf rido los paises del Este luego de la caida del muro de Berlín; y que en Argentina la fuga de talentos representa el 20 por ciento de los emigrantes.

- En la experiencia salvadoreña, estudios de casos estiman en 8.7 grados el promedio educativo de los migrantes ${ }^{5-}$.

La existencia de demanda de trabajo insatisfecha en las economías desarrolladas es una realidad indiscutible, y cada vez con mayor fuerza se está desmitificando la idea que los trabajadores migratorios le quitan cl trabajo a los nacionales: la comparecencia del menor índice de desempleo en la historia reciente de la economía norteamericana se considera que es la mejor prueba sobre este particular.

Además, el mercado laboral norteamericano se ha flexibilizado perversamente con la inmigración ilegal de latinoamericanos, ya que al no existir un equitativo ambiente receptivo, estos se ven obligados a la aceptación de condiciones precarias de trabajo que significan ahorro de costos en la producción, facilitando la competitividad de la economía estadounidense; al grado que el nuevo presidente Vicente Fox ve en los emigrantes mexicanos un "cjército que silenciosamente combate la inflación", en vista de que la mano de obra barata ha permitido mantener bajos los precios en Estados Unidos ${ }^{58}$. 
Los países receptores de migrantes son beneficiarios de la mano de obra barata que provec la inmigración indocumentada: a Estados Unidos se suma España cuyo desarrollo de la agricultura, actividades de hostelería y construcción son favorecidas con el empleo de extranjeros; tambićn ocurre con la economía agricola del sur de Francia, en Grecia con el ingreso de albaneses, el caso arriba citado de Haiti: etc.

Gran parte de los indocumentados centroamericanos realizan trabajos domésticos para los grupos mas acomodados en las ciudades destino de los migrantes a Estados Unidos, facilitando un mayor $y$ más barato bienestar a la clase media; y de limpieza en empresas que dependen de esta oferta de mano de obra.

Sin embargo, a la sombra de acusaciones que los inmigrantes irregulares engrosan las filas de desocupados y/ o empujan los niveles de delincuencia, pululan pasiones xenofóbicas, preocupantes cuando son enarbolados por movimientos neonazis y otros de ultraderecha en Europa.

En ocasiones alcanzan su máxima expresión al ser recogidas por la legislación de los paises receptores, aprobando restricciones con la intención de impedir a los indocumentados el ejercicio de clementales derechos, como son el acceso a la educación y salud. A modo de cjemplo recordamos la demagógica y triste ordenanza 187 que impulsara el Gobernador de California Pete Wilson, por fortuna y justicia ahora derogada y sustituido $\mathrm{el} \mathrm{insigne}$ funcionario por su mismo pucblo. $\mathrm{O} \mathrm{cl}$ proyecto que se discució en España sobre la nueva ley de extranjería, que originalmente pretendia negar derechos de reunión, asociación y huelga a los inmigrantes en situación irregular" finalmente aprobado. Por su parte, el ministro italiano del Interior Enzo Bianco pidió a la EUROPOL que asumiera cl control de las fronteras europeas de alto riesgo en cuanto a trasiego de inmigrantes ilegales y se aplicará a los traficantes que los movilizan la misma legislación que reprime a las organizaciones mafiosas ${ }^{60}$. Medidas promovidas con la crrónea creencia que por enarbolar leyes restricrivas que niegan derechos sociales básicos se frenarían los flujos ilegales de extranjeros, y/o promover un sistema de inmigración que facilite la existencia de una bolsa de trabajo con trabajadores indocumentados para garantizar una mano de obra barata.

La experiencia claramente vaticina que la finalidad es ilusoria y los únicos resultados que efecrivamente provocan son convertir en más penosa la estadia de los inmigrantes y facilitan su explotación en condiciones infames que compiten con las que dejaron en sus lugares de origen, que si bien se explican en los paises del sur por su marcado atraso en desarrollo social, no son justificables en aquellas naciones que han avanzado abismalmente en el reconocimiento $y$ cjercicio de los derechos humanos para su población autóctona y residentes extranjeros en situación regular. Cualidad que constituye un envidiable activo social que debemos aspirar conseruir, haciendo que prevalezca el principio de la igual dignidad de la persona humana independientemente no sólo de su condición social sino también de su origen nacional y estatus de residencia.

Quizás hay una especic de hipocresia en las leyes migratorias estadounidenses, puesto que existen más para disciplinar a la población indocumentada que para evitarla, ya que las deportaciones relativamente no son masivas y se concentran (aunque no exclusivamente) en aquellos que han comerido delitos graves, y a partir de 1996 incluso son sujetos de deportación quienes realizan delitos menores como mancjar en estado de cbriedad, pelear en público, portar pequeñas cantidades de drogas, etc.

Existen acciones civilizadas por su carácter no represivo y consensuado entre las naciones receptoras y los países de origen o de tránsito en dirección a frenar las oleadas de inmigración. Tal es el caso de las consultas periódicas en materia migratoria por parte de los gobiernos de Cuba y Estados Unidos, generándose acuerdos que han permitido desde enero/1995 a la fecha que emigran legalmente más de

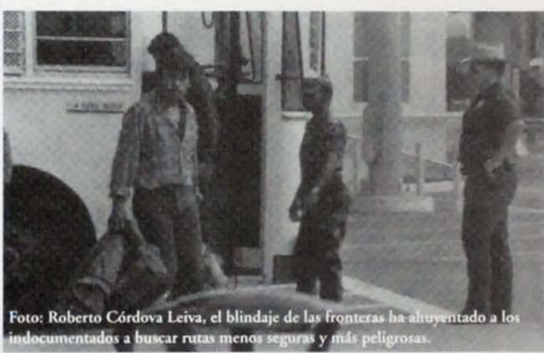

130 mil cubanos a suclo norteamericano ${ }^{61}$; las recientes acciones diplomáticas del Gobierno ltaliano con las autoridades de la vecina Grecia y Turquia, $c$ intenciones de emular similares gestiones con el Gobierno de China por ser uno de los principales países exportadores de inmigrantes a la región curopea.

No todas las conciencias vigilantes de los movimientos poblacionales son contrarios a ellos; observamos hoy en dia una marea ascendente de individuos e instituciones que sostienen actitudes favorables o por lo menos tolerables a la migración, que conforman un abanico de posiciones que van desde la defensa solidaria hasta el interés por conveniencia. 
Hay quienes consideran a los inmigrantes una fuente de riqueza y no ven en estos uno de los mayores problemas del siglo que comienza: como referencia mencionemos que en editorial de un importante periódico español, con motivo del nuevo Censo de Población a realizarse a finales del año, reconoce que "La importancia social y la necesidad económica de la inmigración quedarán de nuevo ratificadas por un estudio que nos va a descubrir a una España bastante diferente de lo que creían los exegetas de las curvas demográficas previsibles $y$ hasta inal terables ${ }^{62}$."

Durante el presente año, el Presidente de la Reserva Federal de Estados Unidos en audiencia con el Congreso, declaró la conveniencia de flexibilizar las puertas a la migración, en aras de sostener y consolidar los resultados del crecimiento económico envidiables que goza esa nación. El Gobernador del Estado de Lowa se ha pronunciado a favor de abrir su territorio a la migración extranjera a fin de compensar la salida de trabajadores locales hacia otros estados atraídos por mejores salarios con la pujanza económica que atraviesan. Incluso existen serias posibilidades que la nación del norte emprenda la importación de mano de obra calificada reduciendo las trabas burocráticas para cubrir el déficit de of erta laboral en ciertas ramas productivas.

Aunque a trancas y barrancas, estas y otras experiencias positivas por el reconocimiento al potencial del inmigrante llevan a inferir que el horizonte revela la tendencia en Norteamérica hacia una especie de liberalización discreta para el mercado de trabajo de profesionales provenientes del extranjero; ojalá como primer paso a una acción de mayor alcance que gradualmente haga realidad la libre movilidad del factor trabajo, sin que por esta aspiración cvitemos reconocer la necesidad que existan, consensuadamente, regulaciones entre unos y otros gobiernos para ordenar los flujos migratorios.

Contener la migración de los países latinoamericanos exigiría de escenarios macroeconómicos por un largo y sostenido periodo de tiempo que al presente y sobre la base de la experiencia parecen situaciones utópicas o de ciencia ficción: convergencia de salarios entre los paises emisores y receptores de la movilidad laboral al estilo imaginado por los autores del teorema arriba citado, decrecientes tasas de desempleo y minimización del fenómeno del subempleo, elevadas tasas de crecimiento económico, etc.

Contra estos escenarios utópicos persiste la realidad de que hay demanda de mano de obra en los países de destino, que estimulan una of erta de inmigrantes en los paises de origen: y similar a los mercados de bienes cuando están sujetos a regulaciones irracionales no funcionales con las necesidades, se crea cl mercado negro, también pasa con las personas y se da nacimiento y consolidación al trafico de ilegales entre paises.

Solo con la supresión de las fronteras humanas se eliminaría este oscuro negocio y daria vigencia a la premisa que "nadie es ilegal donde quicra que viva, porque la idencidad es mas que un documento migratorio y la dignidad no tiene cercos territoriales".

\section{Pena humana. Suerte "envidiable" para el pals}

S e considera que la emigración es una desgracia para $\checkmark$ quienes se ven obligados a abandonar su país con el sueño de encontrar mejores perspectivas para un futuro esperanzador con modelos de vida mas adecuados y humanos, que no seria necesaria si se tuviera trabajo y oportunidades suficientes para gozar de bienestar en los lugares de origen; desdicha mayor si forman parte de los sin papeles, o como Eduardo Galeano llamaria: "los nadic", a quienes se les concibe como objetos antisociales a pesar que bajo la concepción de los derechos humanos ningún hombre o mujer es ilegal.

Diferente a épocas anteriores en las que el migrante viajaba con todo y familia merced al beneplácito de políticas migratorias que impulsaban la movilidad de la mano de obra para satisfacer objetivos expansionistas en las naciones receptoras, desde mediados del siglo pasado la migración por ser inicialmente individual, gradualmente fue conformando una contrapartida económica en la medida que la travesía hacia los lugares de destino además de rodearse de ilegalidad, se dificultaba viajar en compañia de los suyos, tanto por los costos como por el mayor riesgo que significaba distraer atención en el cuido de acompañantes, situación que podría malograr que la aventura fuese exitosa, máxime que el punto de llegada se encuentra a considerable distancia del origen y se tienen que pasar varias fronteras.

Al quedar atrás la parentela (cónyuge, hijos, y/o padres), si bien se produce una fractura del núcleo familiar, surge el compromiso de enviar recursos para el sustento de la familia $y$ a veces también para amortizar hasta cancelar las deudas contraídas para financiar la travesía. Los flujos han sido sostenidos y crecientes, no por un análisis de racionalidad económica que invite a aprovechar que entraran en operación las Casas de Cambio y que llevaron a "sincerar" el precio de las divisas (caso de El Salvador), ya que las motivaciones no son de lucro sino derivadas de lealtades y compromisos con sus comunidades en las que no cuentan cálculos de beneficio económico. Es la necesidad la que empuja enviar remesas independientes que el tipo de cambio este o no administrado por el "libre" mercado, haya o no sobre evaluación.

No son muchas las naciones que reciben cuantiosas ayudas del extranjero, sin mayores compromisos políticos para el gobierno con el país en que residen los filántropos remesistas. El costo no es para el Gobierno sino para la 
sociedad por el desarriego familiar y otras secuelas que arrastran las migraciones que han permitido múltiples beneficios, pero no solo en materia de donaciones para el país como nueva, creciente y consolidada fuente proveedora de divisas y colchón para la acumulación de reservas internacionales.

Fuente a la tendencia a reducirse las donaciones externas oficiales y privadas para el desarrollo, ya que además de que es una moda en los países industriales como una opinión para alcanzar objerivos fiscales desde 1992, ya no padecemos la guerra que propicio envidiable solidaridad, las transferencias familiares por su carácter no reembolsable y cuantía resultan ser una poderosa fuente de ayuda para el progreso, indudablemente mejor que la aspirada en décadas pasada vía deuda externa; a pesar que la fuga de talentos que incluye las migraciones constituye un lamentable despilfarro en nuestro países. Para 1995 se estima que las transferencia de los trabajadores extranjeros a sus paises de origen alcanzaron un montode $\$ 56$, mil ${ }^{63}$, superando la ayuda oficial al desarrollo del sur proveniente del norte.

El Salvador destaca por los flujos en concepto de transferencias privadas muy superiores a los que gozan otras naciones; para efectos comparativos citamos que "en México,

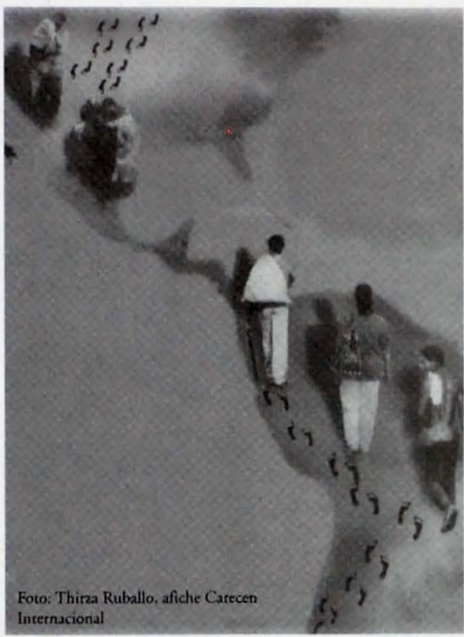

menos para reducir el déficit acumulado en la creación de plazas de trabajo.

Por otra parte, la constante y a veces creciente salida de población, constituye un alivio sobre la demanda de servicios básicos que se demanda del Estado por parte de la sociedad derivada del crecimiento urbano.

No obstante que la mayoría de los salvadoreños que viven en el exterior, individualmente son considerados sectores pobre en Estados Unidos (por tener ingresos menores a \$20 mil), quienes envían remesas relativamente vienen a ser familiares "inmensamente" ricos en un pais como El Salvador, cuyo ingreso per-cápita es inferior a 2 mil 50 dólares. Casi cl 50 por ciento de los salvadoreños viven en situación de pobreza y el 22.3 por ciento en estado de pobreza extrema:

Es incuestionable que el drama de la pobreza en el pais no es mayor, gracias a la ayuda que los familiares trasladan solidariamente a quienes han dejado atrás. El 42 por cient od e quienes reciben estas transferencias externas perciben ingresos menores a 2 mil colones; pero sectores de clase media tambićn son favorecidos ${ }^{\prime * t}$.

Para mayor precisión de csta afirmación, se amerita una investigación que permita verificar quienes son los principales se estima que las remesas representan el 3 por ciento del PIB, en Bangladesh el 3.8 en 1986; en India el 1.6 en 1985; en Paquistán el 10.6 en 1986"64.

Aun cuando nuestros hermanos lejanos lo mas probable es que sean mas infelices que el norteamericano promedio ${ }^{65}$, diríamos que su peor suerte resulta un activo de solidaridad material invaluable para quienes se benefician con los enormes recursos que envian.

La emigración reduce la PEA y en consecuencia baja la oferta de trabajo; si no fuese por la menor presión que existe sobre la existencia del natural ejercito de reserva en una economía con desempleo, el deterioro de los salarios reales seria mas galopante, merced a la brecha (desequilibrio) desfavorable a los trabajadores en el mercado de trabajo, pues el crecimiento y recuperación de la actividad económica no alcanza ni siquiera para cubrir las necesidades de empleo que cada año supone el crecimiento de la población, muchos beneficiarios o receptores de las remesas. Pero existen indicios para suponer que es altamente probable la hipótesis que sin estas remesas, el escenario social seria explosivo.

A pesar que el discurso oficial hace gala de que la estabilidad económica que goza el pais es el resultado del nuevo rumbo adoptado en la politica económica, existe consenso en el reconocimiento del beneficio que sobre esta situación provoca los altos flujos de remesas, además de que financian el desequilibrio comercial. En consecuencia se requiere intentar una profundización en el estudio de las causas y los efectos que la migración de salvadoreños en particular tiene sobre la sociedad, $y$ las supuestas o reales beneficios que se derivan de ella. Solamente asi se superara el actual discurso demagógico en pos de una mesurada actirud que promueva una politica migratoria que no sirva para ocultar $\mathrm{e}$ ignorar vicjos problemas estructurales que son soslayados por cada gobierno de turno 


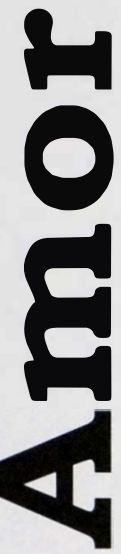

Los que ampliaron el Canal de Panamá

(y fueron clasificados como "silver roll" y no como

los que repararon la flota del Pacifico

"gold roll")

en las bases de California,

Los que se pudrieron en las cárceles de Guatemala, México, Honduras, Nicaragua, por ladrones, por contrabandistas, por estafadores, por hambrientos,

los siempre sospechosos de todo ("me permito remitirle al interfecto por esquinero sospechoso

y con el agravante de ser salvadoreño"),

las que llenaron los bares y los burdeles de todos los puertos y las capitales de la zona ("La Gruta Azul", "El Calzoncito", "Happyland"),

los sembradores de maiz en plena selva extranjera,

los reyes de la página roja, los que nunca sabe nadie de dónde son, los mejores artesanos del mundo, los que fueron cosidos a balazos al cruzar la frontera, los que murieron de paludismo o de las picadas del escorpión o la barba amarilla en el infierno de las bananeras,

los que lloraron borrachos por el himno nacional bajo el ciclón del Pacifico o la nieve del norte, los arrimados, los mendigos, los marihuaneros, los guanacos hijos de la gran puta,

los que apenitas pudieron regresar, los que tuvieron un poco más de suerte, los eternos indocumentados, los hacelotodo, los vendelotodo, los comelotodo,

los primeros en sacar el cuchillo, los tristes más tristes del mundo, mis compatriotas, mis hermanos. 


\section{Migración y remesas familiares; nueva dependencia de la economía}

Citas

' Según el primer Censo poblacional de 1790 casi el 20\% de los habirantes eran negros y casi todos eran escl.tvos. Ver William H. Goetzmann et al. "E.stados Unidos. Una civilizacion", Editorial LABOR, Barcelona, 1975. pag 56

2 Javier Espiago, "Migraciones Exteriores". Colección SALVAT, Barcelona 1982. pag. 18

'William H. Goerzmann, opcitpag 44.

- Puesto que la anterior fue a lo largo del periodo de conquista con la libre inmigración de colonos ingleses y casi paralelo se inicio la inmigración forzada de negros.

\section{'J. Espago op cit pag 11}

${ }^{6}$ Datos elaborados a partir de información contenida en: William $\mathrm{H}$ Goezzmann op cit, y Servicio Cultural e Informativo de los Estados Unidos de América, "Breve Reseña Histórica de los Estados Unidos de América", marzo/1994.

\section{${ }^{7}$ J. Espago op cit pag 23.}

${ }^{8}$ Ibidpag. 28

'Servicio Cultural ... op cit pag. 208

${ }^{10}$ Ibid pag. 201

"Véase Daniel Molina, "El castellano conquista los Estados Unidos", El Clarin, 8/enero/2000

${ }^{12}$ Chistopher Dickey y Jefrey Bartholet, "El nuevo Trafico Internacional", Rev. Newsweek, 5/jul/2000, pag. 13

1 "Eva Marabotto, "La Neurona Subsidiada". CLARIN Digital, 24/septiembre/2000

${ }^{14}$ Luis León Herraiz López, "Migrantes Tejedores de Esperanza"(Manuel Educativo), Centro de Atención al Migrante (CAM), Guatemala, octubrel 1999 pag. 50.

1" Thomas Winschuh. " ¿ Porqué se van ?. Ediciones Heinrich Boll. San Salvador, maızo/1999 pag. 11.

${ }^{16}$ Cociente entre el saldo neto migratorio medio anual y la población media, ambos del mismo periodo.

1: Chistopher Dickey y Jef rey Bartholet, op cit pag. 13

${ }^{18}$ Banco Mundial. Panorama General (versión resumida) pag. 1

19 Chakravarthi Raghavan, "La teoría del comercio internacional. La pobreza es también una industria en crecimiento", Rev. Tercer Mundo Económico, agosto/2000
20 Ibid pag 3.

${ }^{21}$ Ver David Galicia, "Mundo de pobres y ricos". El Ecconomista, 20/sep. tiembre/2000

${ }^{12}$ Enrique Palazuclos, "L a productividad en la economfa de Estados Unidos". El pals Digit al, 16/agosto/2000

${ }^{13}$ Detectores de movimiento, sensores inf rarrojos, dispositivos para ver en la oscuridad y un sistema coordinado por redes de computadoras conectadas a satélites. que forman un muro electrónico como parte de un plan cuyo costo se estima será de $\$ 300$ millones.

24 Como ejemplo citamos las siguientes notas de un arriculo que edito el periódico La Jornada: "San Diego, uastión "conservador, racista y muy antiamericano". Logran Heights, barrio pobre, pero con lujosa estación policial". (06/septiembre/2000)

" La propaganda turística define a Calif ornia como el Golden Satey aseguraque en San Diego vive la "mitad mas rica del estado mas rico del pals mas rico del mundo"... Logan Heights, el sureste de San Diego, concentra un $70 \%$ de personas de origen mexicano. La zona es de clase media baja, roza la pobreza y presenta la oura cara de la moneda.... Pero en Logan esta enclavada una recién construida y casi lujosa estación policial, que es la segunda mas grande de la ciudad después del Departamento de Policía de San Diego donde esta la jef atura .... El edificio es sobrio y a primera vista casi agradable. Su impecable fachada exhibe coloridos simbolos indigenas combinados con azulejos estilo colonial, lo que le da "un toque" mexicano. Pero solo es la fachada: dentro del lugar, entre los agentes de unif orme azul armados hasta los dientes, prevalece una mentalidad de ocupantes de territorio enemigo ... Los agentes baten un récord internacional por la cantidad de implementos represivos que cargan en sus cinturones reglamentarios.. y exhiben sus inevitables lentes negros, a los que definen como un "factor disuasivo ..."

${ }^{24}$ José Antonio Ocampo, "Mas alla del Consenso de Washington: una visión desde la CEPAL". Rev de la CEPAI. No. 66, dic/98, pag. 12

${ }^{26}$ Edward Funkoser. "Mass Migration, Remittance and Economic Adjustment: The Case of El Salvador in the 1980s". Harvard University, 1990, citado en Carlos Orellana Merlos, "M ligración y Remesas. Una Evaluación de su Impacto en la Economía Salvadoreña". CENITEC. Revista Politica Económica, feb-mar/92, pag 3.

Periodico ....................(nov/99) ¿?

${ }^{28}$ Robert D. Putnam y Thad Williamson, "Porqué son inf elices los estadounidenses", El pais Digital. 7/noviembre/2000

29. Lil Jornada, "Sin empleo millones de latinoamericanos". 20/diciembrel 2000.

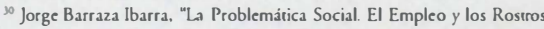
del Desempleo", Rev. Entorno, UTEC, No. XIV, julio/2000, pag. 21

"' J.L. Sánchez, A. Gutiérrez y G. Peces-Berba, "Democracia e Inmigración" El Pais Digital, 7/julio/2000. 
"Héctor Pavon, "Tristezass del Desarraigo", CLARIN Digital, 22/octubre/ 2000.

"Andrew Cockburn, " ¿ Libia. El fin del aislamiento ? ", Rev. National Geographic, nov/2000, pag. 21

* Hay un menú variado de motivaciones para la emigración: políticas, culturales y de diversa indole, que por momentos cobran importancia pero con carácter coyuntural; destacando entre otros factores desencadenantes de grandes desplazamientos humanos: resurgimiento de los nacionalismos violentos que terminan en guerras (caso de los Balcanes), las hambrunas y catástrofes climáticas.

"Como siempre en tcxla regla hay excepciones, tal es el caso de paises como Corea del Sur y Taiwan que tienen elcvadas tasas de emigración, y que relativamente no pueden considerarse naciones pobres.

${ }^{*}$ Elena Valenciano Martinez-Orozco. "Tratico de mujeres en las fronteras de la UE". El País Digital, 23/agosto/2000.

3) Sagrario Azures Orrega, Excélsior, 13/diciembre/2000.

${ }^{85}$ Para referencia se menciona que de los casos atendidos durante 1998 por el Centro de Arención al Migrante (CAM) en la frontera de Guatemala México, el $25 \%$ no tenia familiares en ninguno de los países norteamericanos. Véase L.L. Herraiz op cit pag. 77.

${ }^{39}$ L.L. Herraiz López op cit pag. 56.

"La Jornada, "Del cruce al empleo: La guía del perfecto indocumentado". 20/agosto/2000

"Chistopher Dickey y Jefrey Bartholet, op cit pag. 14

42El Diario de Hoy, 4/agosto/2000

4" El Diario de Hoy, "Derienen ilegales en México", 15/diciembre/2000.

${ }^{44}$ Resulta curioso que en El Salvador también existan quejas y acusaciones por mal trato a extranjeros que transitan por nuestro territorio: por ejemplo, véase la denuncia del embajador de Ecuador en El Salvador en Wendy Ramos, "Atropellos migratorios contra ecuatorianos", La Prensa Gráfica, $8 /$ diciembre/2000.

4s Eduardo Porter y Luis Romo Cedano, "Migración: Abran las Puertas", Rev. América Economia, 08/abr/2000.

${ }^{46}$ La Jornacia, "Del cruce al empleo...."

E. Porter y L. Romo, op cit.

4s Haroldo Sheremul, Excélsior. 04/diciembre/2000.

${ }^{10}$ Charro Villanueva, El Mundo (España), 4/diciembre/2000.

${ }^{50}$ E. Porter y L. Romo, op cit.
"El Pais Digital, "Italia pide que la EUROPOL asuma el control de la inmigracion ilegal en sus fronteras" _/agosto/2000.

12 Manuel Orozco, "Las Remesas hacia Centro America", pag. 3. Trabajo presentado para el proyecto Centroamerica 2020, San Salvador, 5-6 de julio de 1999.

"Como ejemplo vemos que en España "con las abuelas mas longevas de Europa (82.5 años de esperanza de vida en 1999) y con cada vez menos nietos (con un crecimiento demografico cero el año pasado) la necesidad de poblacion se ha transformado en uno de los temas de polemica obligados", Lelio Marmora, "Inmigracion de ida y vuelta", Cl.ARIN Digital, 25/ sepriembre/2000. Y se estima que Alemania, no obstante las altas cifras de desempleados en la actualidad, se vera obligada a importar mano de obra a partir del año 2010 merced a su decreciente natalidad. Vease El Mundo (España) "Schoder quiere retrasar seite años el acceso de los empleados del Este", 19/diciembre/2000.

" El Pais Digital, " Italia pide que la EUROPOL .... "

"Eva Marabotto, op cit.

${ }^{8} \mathrm{lbid}$

${ }^{77}$ Mario Lungo, " Migracion Internacional, Remesase Impacto en las Ciudades ". Rev. Atrernativas para el Desarrollo, FUNDE, 1994 pag. 18

"Henry Tricks (Financial Tmes), "Fox recibe a los heroicos emigrantes de Mexico", El Economisıa, 19/diciembre/2000.

57 Véase El País Digital. "Una ley recordada". 25/septiembre/2000 e "inmigrantes: otra ley", 16/diciembre/2000.

${ }^{60}$ El Pais Digital, "Italia pide que la EUROPO.... "

"Associated Press (AP), " Nueva ronda de negociaciones migratorias entre Cuba y EE.UUn. 7/diciembre/2000.

${ }^{62}$ EL. MUNDO (España). "Seremos 40 millones merced a la inmigración que lo cambia todo", del I3/noviembre/2000.

\section{${ }^{65}$ L.L. Herraiz López, op cit.}

an Mario Lungo y Susan Kandel (compiladores), Ttansformando El Salvador, Migración Internacional, Sociedad y Cultura", FUNDE, octubre 1999. pag. 139.

${ }^{65}$ Quienes ahora, no obstante el envidiable desempeño económico por el que atraviesa el país, se consideran infelices ya que sus participaciones en reuniones en la politica y en reuniones asociativas al año son la mitad de hace 25 años. las cenas familiares son un rercio menos que en los años setenta; lo que significa perdida de vinculos familiares, de amigos y comunitarios. Ver R.D. Putman op cit.

${ }^{*}$ Manuel Orozco op cit. 